\title{
Material Design for Metal Oxide Chemiresistive Gas Sensors
}

\author{
G. Korotcenkov ${ }^{1+}$, S.H. Han², and B.K. Cho ${ }^{1,3+}$
}

\begin{abstract}
Metal oxides designed for application in conductometric gas sensors and approaches used for synthesis of metal oxides with improved gas sensing characteristics are discussed in present article.
\end{abstract}

Keywords : Metal oxides, Gas sensors, Chemiresistors, Material design, Approaches, Optimization

\section{INTRODUCTION}

Conductometric gas sensors (chemiresistors) have a simple structure and their operating principle is based on the fact that their electrical conductivity (or resistance) can be modulated by the presence or absence of some chemical species that comes in contact with the device [1]. Chemiresistors consist of three elements, a sensitive conducting layer, heater and contact electrodes. These electrodes are often interdigitated and embedded in the sensitive layer. To make the measurement, a DC voltage is applied to the device and the current flowing through the electrodes is monitored as the response. The chemical species interact with the sensitive layer and thus modulate its electrical conductivity. This can be measured as a change in the current, which is correlated to the concentration of the chemical species. The main advantages of these sensors are easy fabrication, simple operation, and low production cost, which means that wellengineered metal-oxide conductometric sensors can be mass produced at reasonable cost. Moreover, these sensors

\footnotetext{
${ }^{1}$ Department of Material Science and Engineering, Gwangju Institute of Science and Technology, 261 Cheomdan-gwagiro, Buk-gu, Gwangju 500-712, Korea

2Division of Maritime Transportation System, Mokpo National Maritime University, Mokpo, 530-729, Korea

${ }^{3}$ Department of Nanobio Materials and Electronics, Gwangju Institute of Science and Technology, 261 Cheomdan-gwagiro, Buk-gu, Gwangju 500-712, Korea

${ }^{+}$Corresponding authors: ghkoro@yahoo.com (G. Korotcenkov), chobk@gist.ac.kr (B.K. Cho)

(Received : Sep. 4, 2012, Accepted : Sep. 24, 2012)
}

This is an Open Access article distributed under the terms of the Creative Commons Attribution Non-Commercial License(http://creativecommons.org/licenses /bync/3.0) which permits unrestricted non-commercial use, distribution, and reproduction in any medium, provided the original work is properly cited. are compact and durable. As a result, they are amenable to being used for in situ monitoring [1].

The main processes controlling gas sensing effect are shown in Fig. 1. As it is seen, many various processes and factors influence the operating parameters of conductometric gas sensors. The change in resistance is observed under the effect of reactions such as adsorption, desorption, chemical reactions, surface reconstruction, diffusion, and catalysis, taking place on the surface of the sensing layer.

The most accepted mechanism, explaining sensitivity of $n$-type metal oxide-based sensors, includes consideration of the role of the chemisorbed oxygen [2-4]. Oxygen chemisorption means the formation of $\mathrm{O}_{2}{ }^{-}, \mathrm{O}^{-}, \mathrm{O}^{2-}$ species on the surface. Among these, $\mathrm{O}^{-}$proved to be more reactive than $\mathrm{O}_{2}^{-}$, while $\mathrm{O}^{2-}$ is not stable. So the dominant species is the $\mathrm{O}^{-}$species. It was established that $\mathrm{O}^{-}$species start to be dominant on oxide surface, in particular $\mathrm{SnO}_{2}$, at $T>150-220^{\circ} \mathrm{C}[3,5]$. However, it is necessary to note that some controversy on this subject still persists [4]. The oxygen chemisorption results in a modification of the space charge region toward depletion. At that the amount of charged adsorbates determines both the height of the surface potential $\Phi$ s, as well as the width $d_{\mathrm{s}}$ of the depletion layer. The resistance corresponding to this state is considered the base resistance. The appearance of a reducing gas leads to partial consumption of the adsorbed oxygen, resulting in a decrease in resistance, while the appearance of oxygen increases the surface oxygen coverage, and hence the resistance. The above mechanism suggests the existence of a grain boundary with the space charge region modified by environment [6].

According to Brynzari et al. [7], the influence of some adsorption/desorption parameters on the surface potential 


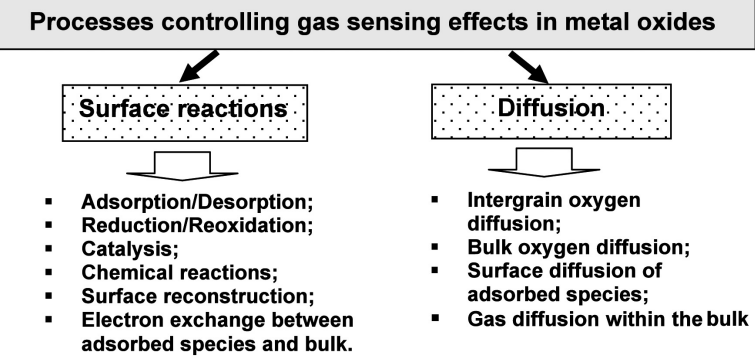

Fig. 1. Processes affecting gas sensitivity of conductometric gas sensors.

$(\Delta U s)$ and $\mathrm{SnO}_{2}$ conductivity $(\Delta G)$ during $\mathrm{CO}$ detection can be presented as the pattern

$$
\frac{\alpha_{R}}{\alpha_{o}} \uparrow, \beta_{4} \uparrow, \beta_{R O} \uparrow, N^{\star} \downarrow, N_{S S} \downarrow, \beta_{3} \downarrow, \beta_{R} \downarrow \Rightarrow \Delta U_{S} \uparrow, \Delta G \uparrow
$$

where $\alpha_{\mathrm{R}}$ and $\alpha_{\mathrm{O}}$ are the coefficients of $\mathrm{R}$ (reducing gas) and $\mathrm{O}_{2}$ adsorption; $\beta_{\mathrm{R}}$ and $\beta_{\mathrm{RO}}$ are the coefficients of $\mathrm{R}$ and $\mathrm{RO}$ desorption; $\beta_{3}$ and $\beta_{4}$ are the coefficients of charging and neutralization of RO; and $N^{*}$ and $N_{s s}$ are the total number of adsorption sites and sites originating from native (biographic) surface charge, $\uparrow$ indicates an increase and $\downarrow$ indicates a decrease. Indicated scheme shows the directions of adsorption/desorption parameters changes, which are necessary to improve sensor response, i.e. increase both the changes of surface potential, and film resistance during interaction with target gas.

Theoretically there are no limitations for using any materials for chemiresistive gas sensor design independently of their either physical, chemical, structural or electrical properties $[1,8,9]$. At present, gas sensor's prototypes on the base of covalent semiconductors, semiconducting metal oxides, solid electrolytes, polymers, ionic membranes, organic semiconductors, and ionic salts have been already tested [10]. However, there are no evidences for assertion that all materials are equally effective for gas sensor applications. Therefore, the selection of optimal sensing material becomes key problem in both design and manufacturing of gas sensor with required operation parameters. At present polymers and metal oxides are the most applied materials for manufacturing chemiresistive gas sensors [10]. However, only metal oxides possess required thermal and temporal stability $[9,10]$. Therefore, in this paper only metal oxides will be discussed.

\section{BINARY METAL OXIDES}

Early works on chemisorption-type sensors (chemiresistors) focused mostly on studying $\mathrm{SnO}_{2}$ and $\mathrm{ZnO}$. Sensors based on these oxides have high sensitivity and rather low operating temperatures, $250-400^{\circ} \mathrm{C}$. These oxides have negligible concentration of electron states in the band gap and high reactivity to many gaseous species. More recently, other oxide materials, such as $\mathrm{WO}_{3}, \mathrm{TiO}_{2}, \mathrm{In}_{2} \mathrm{O}_{3}$, $\mathrm{Ga}_{2} \mathrm{O}_{3}$ etc. have been used successfully to design conductometric gas sensors as well $[9,11-15]$ (see Table 1 ).

The study of other MOXs is a subject of interest to advance various parameters of conductometric sensors. For example, $\mathrm{WO}_{3}$-based gas sensors have excellent selective response to $\mathrm{NH}_{4}, \mathrm{H}_{2} \mathrm{~S}$, and $\mathrm{NO}_{2}$. Moreover, the larger range of sensing materials is required to tailor sensitivity and cross-sensitivity profiles to particular applications and to develop multisensor arrays [1,9]. More detail comparison of metal oxides tested for gas sensor application is given in Table 2 and Table 3.

As summarized in Table 1, MOX gas sensors exhibit broad-range sensitivity to a wide variety of analyte molecules. In all cases a maximum sensitivity occurs in the case of $\mathrm{NO}_{2}$ and $\mathrm{O}_{3}$, which competes with $\mathrm{O}_{2}$ in forming negative surface ion species.

\section{COMPLEX METAL OXIDES AND COMPOSITES}

Except for binary oxides, chemisorption-type conductometric sensors employ complex oxides such as $\mathrm{CdIn}_{2} \mathrm{O}_{4}, \mathrm{NiTa}_{2} \mathrm{O}_{6}, \mathrm{CoTa}_{2} \mathrm{O}_{6}, \mathrm{CuTa}_{2} \mathrm{O}_{6}, \mathrm{BaSnO}_{3}, \mathrm{LnFeO}_{3}$, $\mathrm{CdFe}_{2} \mathrm{O}_{4}, \mathrm{Bi}_{2} \mathrm{Sn}_{2} \mathrm{O}_{7}, \mathrm{YBa}_{2} \mathrm{Cu}_{3} \mathrm{O}_{7-\delta}, \mathrm{Bi}_{\mathrm{x}} \mathrm{Mo}_{\mathrm{y}} \mathrm{O}_{2}, \mathrm{Sn}_{1-\mathrm{x}} \mathrm{Fe}_{\mathrm{x}} \mathrm{O}_{\mathrm{y}}$, $\mathrm{NiFe}_{2} \mathrm{O}_{4}$ and nanocomposites [1, 16, 17]. It was established that highly sophisticated surface-related properties important for gas sensor applications such as optical, electronic, catalytic, mechanical, and chemical can be obtained by advanced nanocomposites synthesized from various materials. For example, metallic and metal-oxide nanoparticles incorporated in various matrixes are capable of increasing the activities for many chemical reactions due to the high ratio of surface atoms with free valences to the cluster of total atoms. As a result, we can obtain an ideal platform for gas sensor design. More complicated metal oxides, for example such as $\mathrm{Li}-\mathrm{SmFe}_{2} \mathrm{O}_{4}, \mathrm{Ni}_{0.99} \mathrm{Co}_{0.01} \mathrm{Mn}_{0.01}$ $\mathrm{Fe}_{1.99} \mathrm{O}_{4}, \mathrm{BaSn}_{0.95} \mathrm{Zr}_{0.05} \mathrm{O}_{3}, \mathrm{Na}_{0.1} \mathrm{Nb}_{0.1} \mathrm{~W}_{0.8} \mathrm{O}_{3}, \mathrm{Cs}_{4} \mathrm{SiW}_{12} \mathrm{O}_{40}$, or 
Table 1. Characterization of conductometric gas sensors based on MOXs

\begin{tabular}{|c|c|c|c|c|}
\hline Material & $\begin{array}{c}\text { Operating } \\
\text { temperature }\left({ }^{\circ} \mathrm{C}\right)\end{array}$ & Implementation & Additives & Target gases \\
\hline $\mathrm{SnO}_{2}$ & $100-500$ & $\begin{array}{l}\text { Ceramic } \\
\text { Thick film } \\
\text { Thin film }\end{array}$ & $\begin{array}{l}\mathrm{Pd}, \mathrm{Pt}, \mathrm{Au}, \mathrm{Sb}, \mathrm{Ag}, \mathrm{Rh}, \mathrm{CuO}, \mathrm{Al}_{2} \mathrm{O}_{3}, \\
\mathrm{In}_{2} \mathrm{O}_{3}, \mathrm{TiO}_{2}, \mathrm{Fe}_{2} \mathrm{O}_{3}, \mathrm{CaO}, \mathrm{Nb}_{2} \mathrm{O}_{5} \\
\mathrm{Bi}_{2} \mathrm{O}_{3}, \mathrm{Mn}, \mathrm{CeO}, \mathrm{La}, \mathrm{MoO}_{3}, \mathrm{SiO}_{2}\end{array}$ & $\begin{array}{l}\mathrm{CO}, \mathrm{C}_{2} \mathrm{H}_{5} \mathrm{OH}, \mathrm{H}_{2}, \mathrm{CCl}_{4}, \mathrm{O}_{3}, \mathrm{CHCl}_{3}, \mathrm{CH}_{4} \text {, } \\
\mathrm{C}_{4} \mathrm{H}_{10}, \mathrm{CH}_{3} \mathrm{CN}, \mathrm{NH}_{3}, \mathrm{SO}_{2}, \mathrm{H}_{2} \mathrm{~S}, \mathrm{NO}, \mathrm{PH}_{3}, \\
\mathrm{NO}_{2}, \mathrm{HF}, \mathrm{O}_{2}, \mathrm{H}_{2} \mathrm{O}, \mathrm{CH}_{2} \mathrm{SH}, \mathrm{C}_{2} \mathrm{H}_{5} \mathrm{OH}\end{array}$ \\
\hline $\mathrm{In}_{2} \mathrm{O}_{3}$ & $50-500$ & $\begin{array}{l}\text { Ceramic } \\
\text { Thick film } \\
\text { Thin film }\end{array}$ & $\begin{array}{l}\mathrm{Pd}, \mathrm{Pt}, \mathrm{Li}_{2} \mathrm{O}, \mathrm{Er}_{2} \mathrm{O}_{3}, \mathrm{GdO}_{3}, \mathrm{WO}_{3}, \mathrm{CaO}, \\
\mathrm{Al}_{2} \mathrm{O}_{3}, \mathrm{SnO}_{2}, \mathrm{SiO}_{2}\end{array}$ & $\begin{array}{l}\mathrm{CO}, \mathrm{O}_{2}, \mathrm{O}_{3}, \mathrm{CH}_{4}, \mathrm{H}_{2}, \mathrm{H}_{2} \mathrm{~S}, \mathrm{HCOH}, \mathrm{NO}_{2} \\
\mathrm{NO}, \mathrm{H}_{2} \mathrm{O}, \mathrm{NH}_{3}, \mathrm{C}_{2} \mathrm{H}_{5} \mathrm{OH}\end{array}$ \\
\hline $\mathrm{WO}_{3}$ & $200-500$ & $\begin{array}{l}\text { Ceramic } \\
\text { Thin film }\end{array}$ & $\mathrm{Sb}, \mathrm{Pt}, \mathrm{Au}$ & $\mathrm{O}_{2}, \mathrm{O}_{3}, \mathrm{H}_{2} \mathrm{~S}, \mathrm{HCOH}, \mathrm{NO}_{2}$ \\
\hline $\mathrm{ZnO}$ & $200-600$ & $\begin{array}{l}\text { Ceramic } \\
\text { Thick film } \\
\text { Thin film }\end{array}$ & $\begin{array}{l}\mathrm{Ni}, \mathrm{Li}_{2} \mathrm{O}, \mathrm{Er}_{2} \mathrm{O}_{3}, \mathrm{WO}_{3}, \mathrm{CaO}, \mathrm{Al}_{2} \mathrm{O}_{3}, \\
\mathrm{In}_{2} \mathrm{O}_{3}, \mathrm{SnO}_{2}\end{array}$ & $\begin{array}{l}\mathrm{O}_{2}, \mathrm{O}_{3}, \mathrm{CO}, \mathrm{H}_{2}, \mathrm{CH}_{4}, \mathrm{NH}_{3}, \mathrm{NO}_{2} \\
\mathrm{C}_{2} \mathrm{H}_{5} \mathrm{OH}\end{array}$ \\
\hline $\mathrm{Ga}_{2} \mathrm{O}_{3}$ & $400-800$ & Thin film & & $\mathrm{O}_{2}, \mathrm{H}_{2}, \mathrm{CO}, \mathrm{CH}_{4}$ \\
\hline $\mathrm{Fe}_{2} \mathrm{O}_{3}$ & $200-500$ & $\begin{array}{l}\text { Ceramic } \\
\text { Thick film } \\
\text { Thin film }\end{array}$ & $\mathrm{Pd}, \mathrm{SnO}_{2}, \mathrm{Mg}, \mathrm{TiO}_{2}, \mathrm{MgO}, \mathrm{SO}_{4}$ & $\mathrm{CH}_{4}, \mathrm{C}_{4} \mathrm{H}_{10}, \mathrm{H}_{2}, \mathrm{CO}, \mathrm{NH}_{3}, \mathrm{~F}_{2}, \mathrm{C}_{2} \mathrm{H}_{5} \mathrm{OH}$ \\
\hline $\mathrm{TiO}_{2}$ & $40-600$ & $\begin{array}{l}\text { Ceramic } \\
\text { Thick film } \\
\text { Thin film } \\
\text { gel }\end{array}$ & $\begin{array}{l}\mathrm{Pt}, \mathrm{Ru}, \mathrm{Au}, \mathrm{Rh}, \mathrm{Cr}, \mathrm{Li}, \mathrm{Na}, \mathrm{In}, \mathrm{Y}, \mathrm{Sr} \\
\mathrm{Tb}, \mathrm{SnO}_{2}, \mathrm{Sb}_{2} \mathrm{O}_{5}, \mathrm{Ta}_{2} \mathrm{O}_{5}, \mathrm{Nb}_{2} \mathrm{O}_{5} \\
\mathrm{Ga}_{2} \mathrm{O}_{3}, \mathrm{CeO}_{2}\end{array}$ & $\begin{array}{l}\mathrm{O}_{2}, \mathrm{H}_{2}, \mathrm{H}_{2} \mathrm{O}, \mathrm{C}_{3} \mathrm{H}_{9} \mathrm{~N}, \mathrm{CO}, \mathrm{NO}_{\mathrm{x}}, \mathrm{C}_{2} \mathrm{H}_{5} \mathrm{OH}, \\
\mathrm{NH}_{3}\end{array}$ \\
\hline $\mathrm{V}_{2} \mathrm{O}_{5}$ & $300-400$ & Thin film & & $\mathrm{H}_{2}, \mathrm{C}_{2} \mathrm{H}_{5} \mathrm{OH}$ \\
\hline $\mathrm{MoO}_{3}$ & $100-500$ & Thin film & $\mathrm{Pt}, \mathrm{ZrO}_{2}$ & $\mathrm{H}_{2}, \mathrm{CO}$ \\
\hline
\end{tabular}

$\mathrm{CoMn}_{0.65} \mathrm{Fe}_{1.35} \mathrm{O}_{4}$, can be used as well. Such complex oxide-based sensors exhibit both $n$-type and $p$-type responses to gases under different operating temperatures. Experiments shown that composites or multicomponent metal oxides may sometimes be promising materials for a specific applications. In particular, Gadkari et al. [16] believe that nickel ferrite $\left(\mathrm{NiFe}_{2} \mathrm{O}_{4}\right)$ can be promising for detection chlorine and acetone, zinc ferrite $\left(\mathrm{ZnFe}_{2} \mathrm{O}_{4}\right)$ for detection ethanol, whereas magnesium ferrite $\left(\mathrm{MgFe}_{2} \mathrm{O}_{4}\right)$ and cadmium ferrite $\left(\mathrm{CdFe}_{2} \mathrm{O}_{4}\right)$ could be used for design LPG and ethanol sensors.

However, experiment has shown that sensors based on such complex oxides usually do not have better gassensing performance compared to sensing materials based on binary oxides. As a rule, the improvement of sensor response was observed only for specific gases such as $\mathrm{H}_{2} \mathrm{~S}$ [18]. The complex nature of these materials also limits their use for integrated gas sensors. The large number of elements in these metal oxides makes it hard to deposit thin films with good and repeatable stoichiometric ratios.

One should remember also that the complication of the composition of gas sensing matrix is always being accompanied by deterioration of sensor parameters' reproducibility. Too many additional factors, which can affect gas sensing properties of materials, appear in nanocomposites. Moreover, one should take into account that sometimes the increase of the sensitivity of devices, elaborated on the base of nanocomposites, is being attained at the expense of worsening other exploitation parameters of sensors. For example, Tamaki et al. [18] have shown that sensors used $\mathrm{SnO}_{2}-\mathrm{CuO}$ composite had higher sensitivity to $\mathrm{H}_{2} \mathrm{~S}$ in comparison with the $\mathrm{SnO}_{2}$ sensors. However, $\mathrm{SnO}_{2} / \mathrm{CuO}$ gas sensing matrix contains $\mathrm{CuO}$ phase, which does not have high thermodynamic stability as compared with $\mathrm{SnO}_{2}$. This fact undoubtedly adversely affects temporal and thermal stability of such sensors' parameters $[9,19]$. The same could be said about $\mathrm{SnO}_{2}$ $\mathrm{Fe}_{2} \mathrm{O}_{3}, \mathrm{In}_{2} \mathrm{O}_{3}-\mathrm{Fe}_{2} \mathrm{O}_{3}$ or $\mathrm{SnO}_{2}-\mathrm{AgO}_{\mathrm{x}}$ composites, showing high sensitivity to several specific gases and vapors.

\section{METAL OXIDE COMPARISON AND SELECTION}

As it follows from Tables 2 and 3 there is no single metal oxide which can satisfy all possible requirements for efficient elaboration of gas sensors [1, 9-12]. This means that we do not have ideal sensing material. All materials have both advantages and shortcomings. Some sensing materials have poor selectivity, some are highly sensitive 
Table 2. Advantages and disadvantages of MOXs for conductometric gas sensor applications

\begin{tabular}{lll}
\hline \hline Material & Advantage & Disadvantages \\
\hline $\mathrm{SnO}_{2}$ & High sensitivity & Low selectivity \\
& Good stability in reducing atmosphere & Dependence on air humidity \\
$\mathrm{WO}_{3}$ & Good sensitivity to oxidizing gases & Low selectivity \\
& Good thermal stability & Low sensitivity to reducing gases \\
& & Dependence on air humidity \\
& High stability & Slow recovery \\
$\mathrm{Ga}_{2} \mathrm{O}_{3}$ & Ability to operate at high temperatures & Low selectivity \\
$\mathrm{In}_{2} \mathrm{O}_{3}$ & High sensitivity to oxidizing gases & Average sensitivity \\
& Fast response and recovery & Low selectivity \\
& Low sensitivity to air humidity & Low stability at low oxygen partial pressure \\
$\mathrm{CTO}(\mathrm{CrTiO})$ & High stability & \\
& Low sensitivity to air humidity & Low selectivity \\
\hline \hline
\end{tabular}

Source: Reprinted with permission from Ref. [9]. Copyright 2007 Elsevier.

Table 3. Operating parameters of metal oxide conductomertic gas sensors and particulars of their fabrication

\begin{tabular}{|c|c|c|c|c|c|c|}
\hline & $\mathrm{SnO}_{2}$ & $\mathrm{WO}_{3}$ & $\mathrm{In}_{2} \mathrm{O}_{3}$ & $\mathrm{ZnO}$ & СТO & $\mathrm{Ga}_{2} \mathrm{O}_{3}$ \\
\hline Optimal gases for detection & $\begin{array}{c}\text { Reducing gases } \\
\left(\mathrm{CO}, \mathrm{H}_{2}, \mathrm{CH}_{4} \text {, etc. }\right)\end{array}$ & $\mathrm{O}_{3}, \mathrm{NO}_{\mathrm{x}}, \mathrm{H}_{2} \mathrm{~S}, \mathrm{SO}_{2}$ & $\mathrm{O}_{3}, \mathrm{NO}_{\mathrm{x}}$ & $\begin{array}{c}\mathrm{CH}_{4}, \mathrm{O}_{3} \\
\mathrm{C}_{4} \mathrm{H}_{10}, \mathrm{NO}_{\mathrm{x}}\end{array}$ & $\begin{array}{c}\mathrm{H}_{2} \mathrm{~S}, \mathrm{NH}_{3}, \mathrm{CO} \\
\text { VOCs }\end{array}$ & $\mathrm{O}_{2}, \mathrm{CO}$ \\
\hline Operating temperature, ${ }^{\circ} \mathrm{C}$ & $200-400$ & $300-500$ & $200-400$ & $250-350$ & $300-450$ & $600-900$ \\
\hline Stability & Excellent & Excellent & Moderate & Satisfactory & High & High \\
\hline $\begin{array}{l}\text { Compatibility with silicon } \\
\text { technologies }\end{array}$ & Imperfect & Low & Good & Good & Imperfect & Good \\
\hline Complexity of fabrication & Acceptable & Moderate & Acceptable & Acceptable & Moderate & Acceptable \\
\hline Sensitivity to air humidity & High & Reduced & Reduced & High & Low & Low \\
\hline $\begin{array}{l}\text { Stability in reducing } \\
\text { atmosphere }\end{array}$ & Good & Good & Moderate & Excellent & Moderate & Moderate \\
\hline $\begin{array}{l}\text { Readiness of synthesis and } \\
\text { deposition }\end{array}$ & High & Medium & High & High & Medium & Medium \\
\hline
\end{tabular}

Source: Data from Ref. [9].

to humidity, some are stable only at low temperatures, some degrade while interacting with ozone, some ones require high temperatures for operating, and so on [10]. Therefore, in choosing a sensing material for a particular application, the selected material should capitalize on its advantages, while its shortcomings should minimally influence the characteristics of the final device. For example, it was established that $\mathrm{SnO}_{2}$-based sensors have better sensitivity to reducing gases, and better stability during operation in reducing atmospheres. However, $\mathrm{In}_{2} \mathrm{O}_{3}$-based sensors have better conductivity response to oxidizing gases, and are less affected by changes in air humidity. Moreover, $\mathrm{In}_{2} \mathrm{O}_{3}$-based ozone sensors have shorter recovery time [12]. Which is better, high response to reducing gases, or to oxidizing gases? Only the designer can answer this question, depending on the requirements for a particular sensor.

The same can be said for other pairs of metal oxides, for example, $\mathrm{SnO}_{2}$-CTO or $\mathrm{SnO}_{2}-\mathrm{WO}_{3}$. Titanium-substituted chromium oxide, $\mathrm{Cr}_{2-\mathrm{x}} \mathrm{Ti}_{\mathrm{x}} \mathrm{O}_{3+\mathrm{z}}(\mathrm{CTO})$, with $0.01<\mathrm{x}<$ 0.45 , has high chemical stability at its operating temperature, an easily measurable range of resistance, and good conductivity response [8]. In contrast to $\mathrm{SnO}_{2}$-based sensors, the effect of water vapor on the parameters of CTO-based sensors, such as the baseline and sensitivity, is much less than that on the parameters of $\mathrm{SnO}_{2}$-based devices operating at the same temperatures. This has been the key to the successful use of CTO-based sensors for detection of carbon monoxide and volatile organic compounds in the air. On the other hand, CTO sensors, 
unlike $\mathrm{SnO}_{2}$ sensors, are not sensitive to methane, though they are sensitive to the higher hydrocarbons and to carbon monoxide, $\mathrm{H}_{2} \mathrm{~S}, \mathrm{NH}_{3}$, and a wide range of solvents.

Considering the pair $\mathrm{SnO}_{2}-\mathrm{WO}_{3}, \mathrm{SnO}_{2}$ shows both large and fast response to ozone at sufficiently low temperature $\left(\sim 200-300^{\circ} \mathrm{C}\right)$, though there are problems of baseline stability at such low temperatures. The effect decreases with increasing temperature, to virtually zero at $400^{\circ} \mathrm{C}$. $\mathrm{WO}_{3}$ shows particularly large resistivity increase at high temperatures $\left(400-500^{\circ} \mathrm{C}\right)$ in response to the presence of ozone. However, the response to ozone is relatively slow, as is the recovery when the gas is removed. In addition, the signal depends on the flow rate of the gas to the surface, and on the partial pressures of water vapor and oxygen [8]. At the same time, however, experiments carried out by Solis et al. [13] showed that $\mathrm{WO}_{3}$-based sensors have unique and excellent sensitivity to low concentrations of $\mathrm{H}_{2} \mathrm{~S}$ in air at room temperature.

Hoefer et al. [14] believe that $\mathrm{Ga}_{2} \mathrm{O}_{3}$-based sensors also have certain advantages in comparison with $\mathrm{SnO}_{2}$-based sensors. $\mathrm{Ga}_{2} \mathrm{O}_{3}$ sensors are high-temperature devices $\left(T_{\text {oper }}\right.$ $=600-900^{\circ} \mathrm{C}$ ) and therefore show faster response and recovery and lower cross-sensitivity to humidity than $\mathrm{SnO}_{2}$-based sensors. $\mathrm{Ga}_{2} \mathrm{O}_{3}$ sensors also show stable longterm sensing properties and good reproducibility even in sulfur-containing atmospheres. This last property makes these sensors suitable for use in domestic burner controls. No cleaning cycles are necessary, and smut or other organic residues are burned off. Additionally, no pre-aging is necessary (compared to $\mathrm{SnO}_{2}$ ). On the other hand, the sensitivity of $\mathrm{Ga}_{2} \mathrm{O}_{3}$ sensors to a number of gases is lower compared to $\mathrm{SnO}_{2}$-based sensors, and the power consumption of $\mathrm{Ga}_{2} \mathrm{O}_{3}$-based sensors is comparably high due to their high operating temperatures.

Grimes and co-workers [15] found that $\mathrm{TiO}_{2}$ nanotubes were excellent room-temperature hydrogen sensors not only with a high sensitivity but also with an ability to selfclean photoactively after environmental contamination. The hydrogen-sensing capabilities of the sensors were largely recovered by ultraviolet (UV) light exposure after being completely extinguished by a rather extreme means of sensor contamination: immersion of the sensor in motor oil. $\mathrm{SnO}_{2}$ does not possess such properties.

All these factors mean that the choice of a metal oxide for gas sensor design is determined by the type of gas sensor to be designed, the apparatus or device in which the sensor will be used, the structure chosen for the sensor's fabrication, and conditions of exploitation. However, any competition between potential materials can be ignored if the device is to become part of an "electronic nose." Different behavior during interaction with the same gas is one of the most important requirements for sensors designed for this application $[9,10]$.

\section{IMPROVEMENT OF GAS SENSING PARAMETERS THROUGH MATERIAL OPTIMIZATION}

\subsection{Conventional Approaches}

Conducted research have shown that gas sensing effect in metal oxides is very complicated phenomenon, which depends on all metal oxide parameters, such as thickness, grain size, porosity, grain faceting, agglomeration, bulk conductivity, surface architecture, grain network, surface stoichiometry, catalytic reactivity, band gap and so on (see Fig. 2) [1, 20-23]. Analysis carried out has shown that the influence of above mentioned parameters on gas sensing characteristics takes place through the change of parameters such as effective area of intergrain and interagglomerate contacts, energetic parameters of adsorption/desorption processes, number of surface sites, concentration of charge carriers, initial surface potential, coordination number of metal atoms on the surface, gas penetrability of sensing matrix, etc. [24, 25].

At present, material engineering of metal oxide films is one of the most effective methods used for optimization of solid state gas sensors $[23,24,26]$. The considerable improvement of operating parameters such as sensor signal, selectivity, stability and the rate of sensor response can be achieved due to optimization of chemical, structural, bulk and surface properties of applied metal oxides.

There are a great number of technological methods, which could be used for optimization of sensor parameters (see Fig. 3). It was shown that deposition parameter control, post deposition treatments and doping during synthesis and deposition processes really influence all properties of metal oxides important for gas sensor applications. For example, the increase of pyrolysis temperature during $\operatorname{In}_{2} \mathrm{O}_{3}$ and $\mathrm{SnO}_{2}$ deposition reduces the influence of water vapor on the conductivity of these metal oxides and respectively on sensor response. The surface modification by noble metals promotes the improvement of sensitivity and decrease of response and recovery times. The use of one-dimensional metal oxides improves thermal stability of structure and 
properties. The metal oxide doping by noble and transition metals modifies the catalytic reactivity and morphology of deposited films, etc. [1].

However, the same researches have shown that the elaboration of sensors with optimal gas sensing characteristics is really very complicated task. At that, in spite of great technological possibilities, there is no universal decision for simultaneous optimization of all sensor parameters. As a rule, an improvement of one parameter is accompanied by worsening of another one. For example, numerous investigations have shown that the decreasing crystallite size leads to an increase of gas sensitivity. A dramatic increase in sensitivity for metal oxides with grain size smaller than a Debye length has been demonstrated many times for various materials, such as $\mathrm{SnO}_{2}, \mathrm{WO}_{3}, \mathrm{In}_{2} \mathrm{O}_{3}$ etc. [24, 27-29]. For $\mathrm{In}_{2} \mathrm{O}_{3}$ this effect is illustrated in Fig. 4.

For $\mathrm{In}_{2} \mathrm{O}_{3}$, it was also found that sensors fabricated using thin films with minimal crystallite size had minimal response time in addition to maximum sensor response, especially to ozone [30]. Therefore, at present polycrystalline materials with nano-dimensional grains are most often considered as a basis for prospective gas sensors.

However, it was established that the decrease of grain size decreases thermal and temporal stability of designed gas sensor [28, 31]. It was shown that for $\mathrm{SnO}_{2}$ grains with size about $1-4 \mathrm{~nm}$, grain growth process begins already at

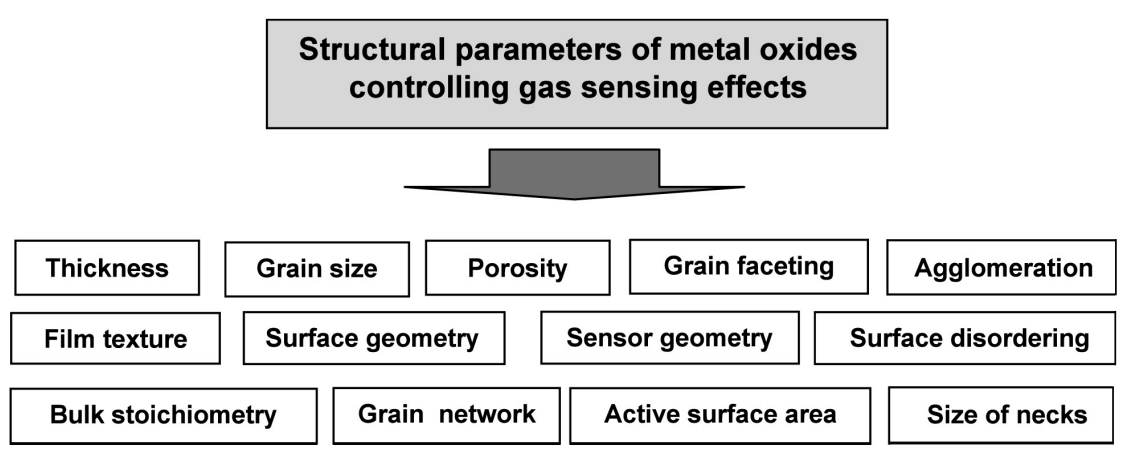

Fig. 2. Structural parameters of MOXs that control their gas-sensing properties. Reprinted with permission from Ref. [24]. Copyright 2008: Elsevier.

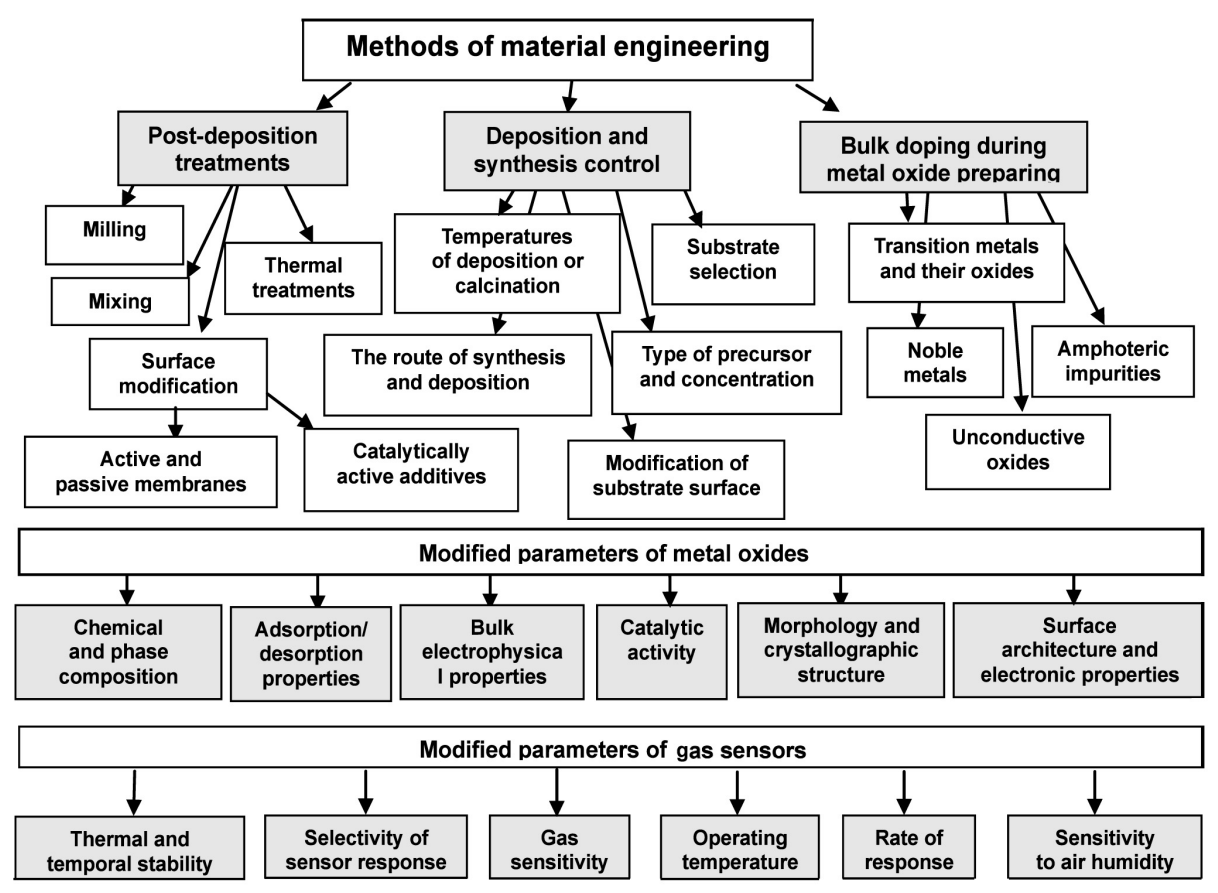

Fig. 3. Diagram illustrating methods of structural engineering used for optimization of solid state gas sensor parameters. 
temperatures equaled $\sim 200-400{ }^{\circ} \mathrm{C}$ (see Fig. 5).

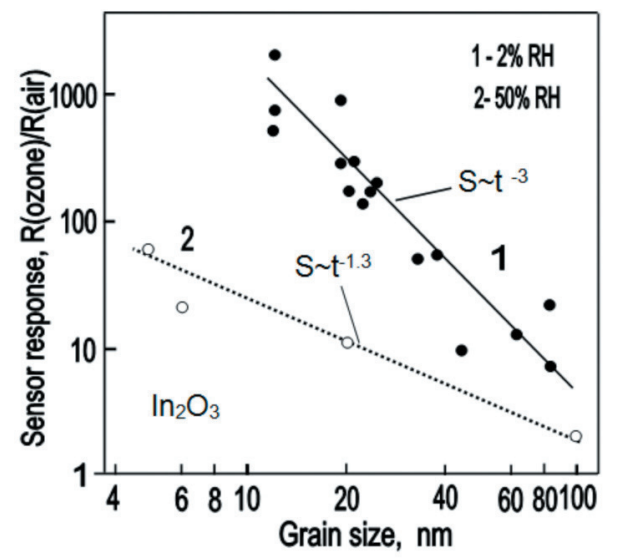

Fig. 4. Influence grain size on sensor response to (1) ozone $(\sim 1$ ppm) and (2) $\mathrm{NO}_{2}(\sim 1 \mathrm{ppm})$ of undoped $\mathrm{In}_{2} \mathrm{O}_{3}$-based devices. (1) Thin-film technology. (2) Thick-film technology. Experimental data from Ref. [30] and Ref. [29].

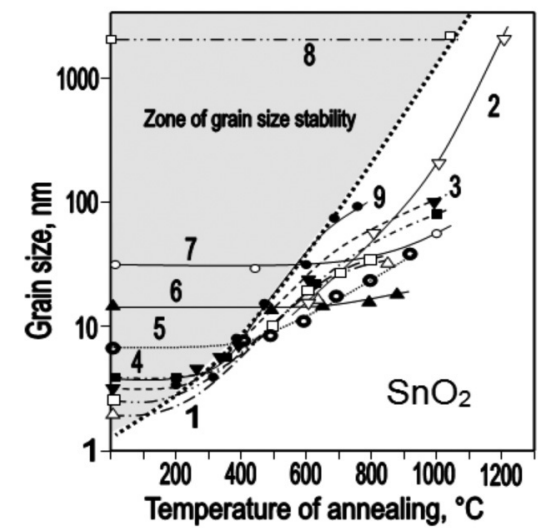

Fig. 5. Influence of annealing temperature on grain size in $\mathrm{SnO}_{2}$ films synthesized using different manufacturing methods. Reprinted with permission from Ref. [32]. Copyright 2005: Elsevier.

This means that the presence of fine-dispersed fraction with grain size smaller then $1-5 \mathrm{~nm}$ leads to some structure instability of metal oxide matrix in the range of operating temperatures $\left(T<600^{\circ} \mathrm{C}\right)$ even for films with average grain sizes more than $50 \mathrm{~nm}$. The increase of sensitivity to humidity is also observed for sensors with small grain size [28]. Therefore, a compromise between high sensitivity and high temporal and thermal stability is required. It is foreseen that in the future the design of methods of grain size stabilization during long-term exploitation of nanoscale devices will gain priority over the design of methods, producing nano-scaled materials with minimal grain size.

The similar situation takes place for materials, modified by catalitically active additives. As it was shown, catalytically active additives, especially noble metals, can essentially increase sensitivity. However, at the same time they might be one of the reasons of observed temporal instability of gas sensor parameters [19].

The same we can say about bulk doping of metal oxides, which can be used for improvement of sensitivity, selectivity and stability of gas sensors $[11,19,23]$. The process of bulk doping in very complicated one, which is accompanied by the change of all parameters of metal oxide matrix, even in the case of small concentration of additives (see Fig. 6).

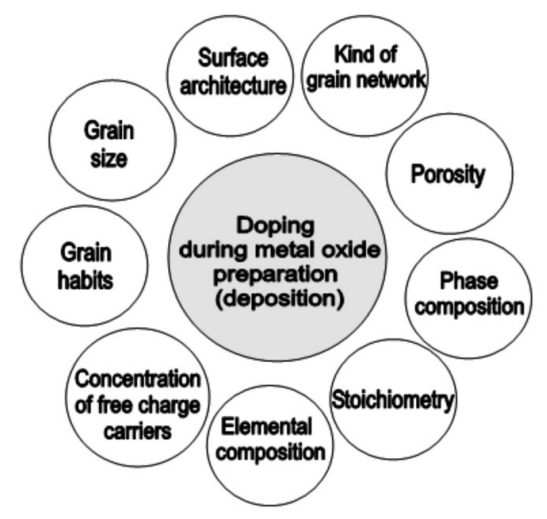

Fig. 6. Parameters of metal oxides, which are dependent on the bulk doping.

Therefore, researchers have to be careful during the elaboration of technologies of gas sensing layers' forming on the base of doped and multi-component materials. When you choose additives for film structure optimization or stabilization, one should take into account, that the optimization of sensor response takes place usually only for concentrations of additives in the range from 0.05-3 wt. $\%$ and the superfluous concentration of these additives sharply reduces the sensor response (see Fig. 7).

We need to take into account that for high concentration of additives we will observe the precipitation of second phase in the matrix of based metal oxide [33]. Moreover, in real situation, as a rule, the concentration of doping, which is optimal for improvement of gas sensing characteristics, is not sufficient for improvement structural stability of metal oxides [31]. Moreover, instead of anticipated improvement of structural stability you can obtain considerable worsening of this parameter [34]. The last one, as a rule, is a consequence of increase of fine dispersed phase contents in metal oxide matrix. 


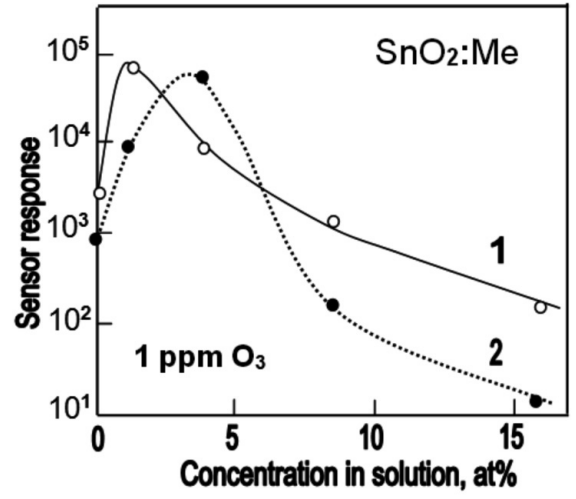

Fig. 7. Influence of $\mathrm{SnO}_{2}$ doping by (1) $\mathrm{Fe}$ and (2) Co during film deposition by spray pyrolysis on response to ozone: $T_{\text {pyr }}=$ $410-420{ }^{\circ} \mathrm{C}$; $d \sim 45-55 \mathrm{~nm}$. Reprinted with permission from Ref. [23]. Copyright 2005: Elsevier.

\subsection{1-D Metal Oxide Structures}

At present many of researchers believe that the use of 1D nanostructures is one of the main trends in gas sensors design [10]. It is truth, because results obtained during study of one-dimensional metal oxide nanomaterials have great importance due to their potential for fundamental studies of gas sensing effects as well as for design lowcost, small-sized, and low-power consumption devices [1]. One-dimensional metal oxide nanomaterials have excellent crystallinity and clear facets (Table 4). Moreover onedimensional structures can be synthesized using inexpensive, simple technology. It is expected that these nanomaterials will have less concentration of point defects and specific adsorption and catalytic properties, conditioned by a particular combination of crystallographic planes. In addition, one-dimensional metal oxide nanomaterials should be more thermodynamically stable in comparison to nanograins, promoting stable operation of gas sensors at higher temperatures.

Development of nanotechnology gives hope for realizing gas sensors based on one-dimensional metal oxide nanowires with parameters improved relative to devices based on polycrystalline materials [1, 10, 24]. Achievements in the field of gas sensor design are listed in Table 5.

Wide use of one-dimensional structures is however impeded by the great difficulties required for their separation and manipulation. During the synthesis process of one-dimension structures one may observe a considerable diversity in their geometric parameters. Therefore, reproducibility of performance parameters for sensors based on individual one-dimension structures would depend on the uniformity of those structures. Moreover, technological approaches used in manufacturing sensors based on individual 1-D structures differ fundamentally from the methods used in standard silicon technology. As a result, while working with individual 1-D structures we face great difficulties with integration in silicon technology $[1,10]$. Unfortunately, the problem of separation, sizing, and manipulations of one-dimensional structures is not resolved yet. To achieve uniform sizing and orientation, new advanced technologies will need to be implemented, and these would be expensive and not accessible for wide use. Therefore, gas sensors based on individual one-dimension structures are not yet readily available commercially. Further, the manufacturing cost of sensors based on one-dimensional structures would far exceed that of polycrystalline devices. Based on what was said above, it becomes clear that in near future, polycrystalline materials would remain the dominant platform for solid-state gas sensors [24].

\subsection{Mesoporous, Macroporous and Hierarchical Metal Oxide Structures}

Mesoporous, macroporous and hierarchical metal oxide structures is other modern direction in design of sensing materials for conductometric gas sensors. It was established that the ability to create macroporous objects from nanoscaled components may create new resources for optimization of gas sensor parameters. The pores in 3-D MOX structures are developed in the submicrometer or nanodimensional domain. Therefore, these structures are frequently called mesoporous. These rather new materials with extremely high surface area offer a high degree of versatility in terms of structure and texture. The most successful approaches to developing mesoporous structures are based on synthesis of pore-containing particles via templating or via a facile wet-chemical approach combining with an annealing process [57].

The hierarchical nanostructures have also extremely high surface area and have little tendency to agglomerate, which allows one to employ them as high-performance gas sensor materials. A 'hierarchical structure' means the higher dimension of a micro- or nanostructure composed of many, low dimensional, nano-building blocks [58]. The various hierarchical structures can be classified according to the dimensions of nano-building blocks and the consequent hierarchical structures, referring to the dimensions, 
Table 4. Crystallographic geometry of one-dimensional oxide nanostructures

\begin{tabular}{|c|c|c|c|c|}
\hline Nano-structures & Crystal structure & Growth direction & Top surface & Side surface \\
\hline ZnO-belt & Wurtzite & (0001) or (01-10) & $\pm(2-1-10)$ & $\pm(01-10)$ or $\pm(0001)$ \\
\hline $\mathrm{Ga}_{2} \mathrm{O}_{3}$-belt & Monoclinic & $(001)$ or $(010)$ & $\pm(100)$ & $\pm(010)$ or $\pm(10-1)$ \\
\hline $\mathrm{Ga}_{2} \mathrm{O}_{3}$-sheet & Monoclinic & (101) (normal) & $\pm(100)$ & $\begin{array}{l} \pm(010) \\
\pm(10-1) \text { and } \pm(21-2)\end{array}$ \\
\hline $\mathrm{t}-\mathrm{SnO}_{2}$-belt & Rutile & (101) & $\pm(10-1)$ & $\pm(010)$ and $\pm(10-1)$ \\
\hline $\mathrm{SnO}_{2}$-belt & Rutile & (100) & $\pm(001)$ & \\
\hline $\mathrm{t}-\mathrm{SnO}_{2}$-wire & Rutile & (101) & $\pm(10-1)$ & $\pm(010)$ \\
\hline $\mathrm{SnO}_{2}$-belt(zigzag-initial) & Rutile & (101) & $\pm(010)$ & $\pm(10-1)$ and $\pm(100)$ \\
\hline $\mathrm{SnO}_{2}$-belt(zigzag-final) & Rutile & (101) & $\pm(010)$ & $\pm(100)$ \\
\hline$\alpha-\mathrm{SnO}_{2}$-wire & Orthorhombic & (010) & $\pm(100)$ & $\pm(001)$ \\
\hline $\mathrm{SnO}_{2}$-diskette & Tetragonel & $\pm(100)$ and $\pm(110)$ & $\pm(001)$ & $\pm(100)$ and $\pm(110)$ \\
\hline $\mathrm{SnO}_{2}$-ribbon & Rutile & (101) & $(10-1) /(-101)$ & $(010) /(0-10)$ \\
\hline $\mathrm{SnO}_{2}$-ribbon(sandwich) & Rutile/orhorom. & $(110)_{\mathrm{o}} /(6-53)_{\mathrm{t}}$ & $\pm(100) \mathrm{o} / \pm(231)_{\mathrm{t}}$ & $\pm(001)_{\mathrm{o}} / \pm(10-1)_{\mathrm{t}}$ \\
\hline
\end{tabular}

Source: Data from Refs. [24,35,36,37,38].

Table 5. Parameters of gas sensors based on single 1D oxide nanostructure classified by tested gas

\begin{tabular}{|c|c|c|c|c|c|}
\hline Target gas & Material (Sensor type) & Detection limit (Temp.) & Sensitivity (Conc.) & Response time & Ref. \\
\hline $\mathrm{NO}_{2}$ & $\begin{array}{c}\mathrm{SnO}_{2}(\mathrm{nr}-\mathrm{R}) \\
\mathrm{SnO}_{2}(\mathrm{nw}-\mathrm{R}) \\
\mathrm{In}_{2} \mathrm{O}_{3}(\mathrm{nw}-\mathrm{FET}) \\
\mathrm{In}_{2} \mathrm{O}_{3}(\mathrm{nw}-\mathrm{FET}) \\
\mathrm{ZnO}(\mathrm{nw}-\mathrm{R})\end{array}$ & $\begin{array}{c}2 \operatorname{ppm}\left(25^{\circ} \mathrm{C}\right) \\
<0.1 \mathrm{ppm}\left(25^{\circ} \mathrm{C}\right) \\
0.5 \operatorname{ppm}\left(25^{\circ} \mathrm{C}\right) \\
0.02 \mathrm{ppm}\left(25^{\circ} \mathrm{C}\right) \\
<0.1 \operatorname{ppn}\left(225^{\circ} \mathrm{C}\right)\end{array}$ & $\begin{array}{c}7(100 \mathrm{ppm}) \\
1(10 \mathrm{ppm}) \\
10^{6}(100 \mathrm{ppm}) \\
0.8(1 \mathrm{ppm}) \\
100(20 \mathrm{ppm})\end{array}$ & $\begin{array}{l}\sim 1 \mathrm{~min} \\
\sim 1 \mathrm{~min} \\
5 \mathrm{~s} \\
15 \mathrm{~min} \\
24 \mathrm{~s}\end{array}$ & $\begin{array}{l}{[39]} \\
{[40]} \\
{[41]} \\
{[42]} \\
{[43]}\end{array}$ \\
\hline $\mathrm{H}_{2}$ & $\begin{array}{c}\mathrm{SnO}_{2}(\mathrm{nw}-\mathrm{FET}) \\
\mathrm{VO}_{2}(\mathrm{nw}-\mathrm{R}) \\
\mathrm{WO}_{2.72}(\mathrm{nw}-\mathrm{R})\end{array}$ & $\begin{array}{c}<1 \mathrm{ppm}\left(200^{\circ} \mathrm{C}\right) \\
\mathrm{N} / \mathrm{A}\left(50^{\circ} \mathrm{C}\right) \\
<100 \mathrm{ppm}\left(25^{\circ} \mathrm{C}\right)\end{array}$ & $\begin{array}{c}4(1 \mathrm{ppm}) \\
1000(100 \%) \\
22(1000 \mathrm{ppm})\end{array}$ & $\begin{array}{c}\sim 50 \mathrm{~s} \\
\sim 10 \mathrm{~min} \\
40 \mathrm{~s}\end{array}$ & $\begin{array}{l}{[44]} \\
{[45]} \\
{[46]}\end{array}$ \\
\hline $\mathrm{CO}$ & $\begin{array}{c}\mathrm{SnO}_{2}(\mathrm{nb}-\mathrm{R}) \\
\mathrm{SnO}_{2}(\mathrm{nw}-\mathrm{FET}) \\
\mathrm{ZnO}(\mathrm{nw}-\mathrm{R}) \\
\mathrm{NiO}(\mathrm{nw}-\mathrm{R}) \\
\mathrm{CeO}_{2}(\mathrm{nw}-\mathrm{R})\end{array}$ & $\begin{array}{c}5 \operatorname{ppm}\left(400^{\circ} \mathrm{C}\right) \\
100 \mathrm{ppm}\left(25^{\circ} \mathrm{C}\right) \\
<50 \operatorname{ppm}\left(275^{\circ} \mathrm{C}\right) \\
\text { N/A }\left(150^{\circ} \mathrm{C}\right) \\
<10 \mathrm{ppm}\left(25^{\circ} \mathrm{C}\right)\end{array}$ & $\begin{array}{c}7(250 \mathrm{ppm}) \\
15(500 \mathrm{ppm}) \\
3200(400 \mathrm{ppm}) \\
0.25(800 \mathrm{ppm}) \\
2(200 \mathrm{ppm})\end{array}$ & $\begin{array}{c}30 \mathrm{~s} \\
\sim 10 \mathrm{~min} \\
\sim 50 \mathrm{~min} \\
\sim 2 \mathrm{~h} \\
\sim 10 \mathrm{~s}\end{array}$ & $\begin{array}{l}{[47]} \\
{[48]} \\
{[49]} \\
{[50]} \\
{[51]}\end{array}$ \\
\hline $\mathrm{H}_{2} \mathrm{~S}$ & $\begin{array}{c}\mathrm{SnO}_{2}(\mathrm{nw}-\mathrm{R}) \\
\mathrm{ZnO}(\mathrm{nw}-\mathrm{R}) \\
\mathrm{In}_{2} \mathrm{O}_{3}(\mathrm{nw}-\mathrm{FET})\end{array}$ & $\begin{array}{c}<1 \mathrm{ppm}\left(150^{\circ} \mathrm{C}\right) \\
\text { N/A }\left(25^{\circ} \mathrm{C}\right) \\
1 \mathrm{ppm}\left(25^{\circ} \mathrm{C}\right)\end{array}$ & $\begin{array}{c}6 \times 10^{6}(50 \mathrm{ppm}) \\
8(300 \mathrm{ppm}) \\
1(20 \mathrm{ppm})\end{array}$ & $\begin{array}{l}\mathrm{N} / \mathrm{A} \\
\sim 50 \mathrm{~s} \\
48 \mathrm{~s}\end{array}$ & $\begin{array}{l}{[52]} \\
{[53]} \\
{[54]}\end{array}$ \\
\hline Ethanol & $\mathrm{SnO}_{2}(\mathrm{nt}-\mathrm{R})$ & N/A $\left(400^{\circ} \mathrm{C}\right)$ & $20(7.8 \%)$ & $\sim 80 \mathrm{~s}$ & [55] \\
\hline $\mathrm{O}_{2}$ & $-\mathrm{Ga}_{2} \mathrm{O}_{3}(\mathrm{nw}-\mathrm{R})$ & $<50 \operatorname{ppm}\left(25^{\circ} \mathrm{C}\right)$ & $20(50 \mathrm{ppm})$ & $1 \mathrm{~s}$ & [56] \\
\hline
\end{tabular}

Sensitivity $\left(\mathrm{R}_{\mathrm{gas}} / \mathrm{R}_{\mathrm{air}}\right.$ or $\left.\mathrm{R}_{\mathrm{gas}} / \mathrm{R}_{\mathrm{air}}\right)$; R- resistive; nw -nanowire; nt- naotube; nb-nanobelt; nr-nanoribbon

respectively, of the nano-building blocks and of the assembled hierarchical structures (see Fig. 8). For example, '1-3 urchin' means that 1D nanowires/nanorods are assembled into a 3D urchin-like spherical shape and '2-3 flower' indicates a the 3D flower-like hierarchical structure that is assembled from many 2D nanosheets. Under this framework, the hollow spheres can be regarded as the assembly of 1D nanoparticles into the 3D hollow spherical shape. Thus, strictly speaking, the 0-3 hollow spheres should be regarded as one type of the hierarchical structures.

Various methods have been considered for synthesizing such hierarchical hollow-particle structures, including spray drying [59, 60], sol-gel [61], layer-by-layer (LbL) templating [62, 63], electrodeposition [64], vapor-phase impregnation [65], interface growth, pulse laser deposition, and others [66]. However, the most promising technologies seem to be methods based on sol-gel, aerosol spray and 


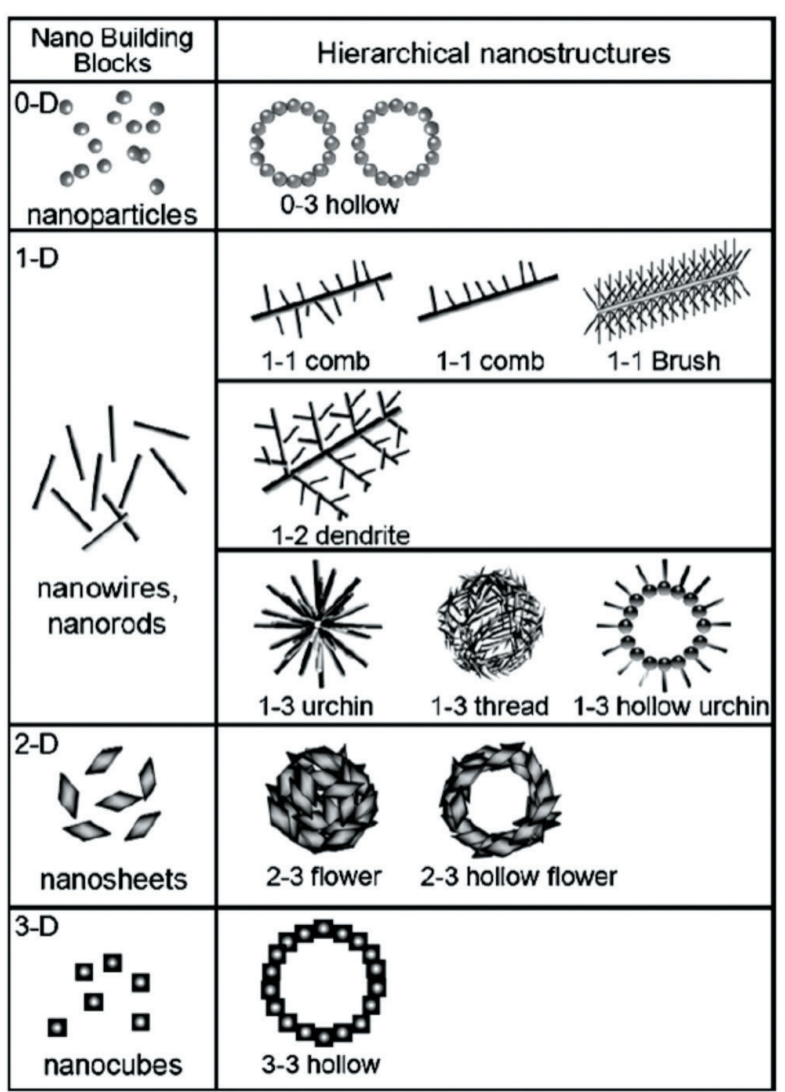

Fig. 8. Nomenclature of hierarchical structures according to the dimensions of the nano-building blocks (the former number) and of the consequent hierarchical structures (the latter number). (Reprinted with permission from Ref. [58]. Copyright 2009 Elsevier.)

LbL deposition [58]. From our point of view electrochemical etching of metal films with following oxidation of fabricated porous structure is also very promising approach to design of mesoporuus gas sensing matrix. Such approach was discussed with reference to $\mathrm{TiO}_{2}$ and $\mathrm{SnO}_{2}$ in Refs. [67-69] and [70], correspondingly.

It is necessary to note that technologies for fabricating mesoporous and hierarchical nanostructures have been developed for all the basic MOXs $\left(\mathrm{SnO}_{2}, \mathrm{In}_{2} \mathrm{O}_{3}, \mathrm{TiO}_{2}\right.$, $\mathrm{WO}_{3}, \mathrm{Fe}_{2} \mathrm{O}_{3}$, etc.) utilized to develop conductometric gas sensors [58]. The gas-sensing performance of sensors based on mesoporous and hollow nanostructures is well reviewed elsewhere $[58,71]$, and it is agreed that such structures are really attractive platforms for gas-sensing applications [65, 72, 73]. Mesoporous and hollow structures have been reported to show very high gassensing response [74-76] and fast response kinetics [77], which are attributed to their high surface area and welldefined porous architecture. Especially big difference in kinetics of sensor response was observed in comparison with sensors fabricated using agglomerated powders [78].

At that it was established that the hollow nanostructures follow the same basic trends as we mentioned for the thinfilm layers. When the shells are rather dense and thick, the gas-sensing reaction occurs only near the surface of the hollow spheres, and the inner parts of these spheres are inactive. However, if the shell is sufficiently thin, the primary particles in the entire hollow sphere are able to participate in gas-sensing reactions even when the shells are less permeable. In addition, the rate of sensor response of hollow spheres increases with the thinner shell configuration due to the faster gas diffusion. It has been also found that the sensor response and response kinetics of the mesoporous sensing materials similarly to conventional metal oxide matrix can be improved further by surface modification [75] and doping by catalytic materials [79-81].

It is necessary to note that the problem of structural instability exists for all types of mentioned above structures independently of material used. Moreover, resolving this problem does not have universal approach. Unfortunately, every material used for mesoporous, macroporous and hollow staructures fabrication requires specific approach to resolving. For example, Shimizu and co-workers [82] found that the most important key to the drastic improvement of thermal stability of mesoporous $(m-) \mathrm{SnO}_{2}$ powders is to immerse them in a phosphoric acid aqueous solution before calcination and consequently loading of phosphorous-components on the surface of $m-\mathrm{SnO}_{2}$ crystallites. Such treatment enabled to prepare the $m-\mathrm{SnO}_{2}$ powders with small crystallite size $(2 \sim 3 \mathrm{~nm}$ in diameter) and large specific surface area $\left(>300 \mathrm{~m}^{2} / \mathrm{g}\right)$ even after calcination at $600^{\circ} \mathrm{C}$.

\subsection{Nanofiber}

Of course, metal oxide nanofibers are not 1-D structures in classical understanding as nanotubes or nanowires. However, nanofibers, which usually have diameter in the range of 10-1000 nm and the length from several $\mu \mathrm{m}$ up to $\mathrm{cm}$ and meter, possess many unique properties since these fibers have also very large surface area per unit mass and small pore size. For preparing nanofibers can be used various methods, including drawing, hard and soft template synthesis, self-assembly, and electrospinning. Among these methods, electrospinning seems to be the simplest and most versatile technique capable of generating metal oxide nanostructures. 
Table 6. Characteristics of several metal oxide nanofiber-based conductometric gas sensors

\begin{tabular}{lcccccc}
\hline \hline \multicolumn{1}{c}{ Material } & Array & Fibber diameter $(\mathrm{nm})$ & Gases tested & $T_{\text {oper }}\left({ }^{\circ} \mathrm{C}\right)$ & Detection limit & Ref. \\
\hline $\mathrm{TiO}_{2}$ & $\mathrm{~N}$ & $200-500$ & $\mathrm{NO}_{2}$ & $150-400$ & $500 \mathrm{ppb}$ & {$[90]$} \\
$\mathrm{TiO}_{2}$ & $\mathrm{~N}$ & $120-850$ & $\mathrm{CO}, \mathrm{NO}_{2}$ & $300-400$ & $50 \mathrm{ppb}$ & {$[92]$} \\
$\mathrm{TiO}_{2}$ & $\mathrm{~N}$ & $400-500$ & $\mathrm{CO}$ & 200 & $<1 \mathrm{ppm}$ & {$[89]$} \\
${\mathrm{LiCl}-\mathrm{TiO}_{2}}_{\mathrm{SnO}_{2}}$ & $\mathrm{~N}$ & $150-260$ & $\mathrm{H}_{2} \mathrm{O}$ & $\mathrm{RT}$ & $11 \%$ & {$[96]$} \\
$\mathrm{SnO}_{2}$ & $\mathrm{~S}$ & 700 & $\mathrm{H}_{2} \mathrm{O}$ & $\mathrm{RT}$ & $\mathrm{N} / \mathrm{A}$ & {$[94]$} \\
$\mathrm{MWCNT}$ & $\mathrm{N}$ & $\sim 100$ & $\mathrm{C}_{2} \mathrm{H}_{5} \mathrm{OH}$ & 330 & $10 \mathrm{ppb}$ & {$[91]$} \\
$\mathrm{In}_{2} \mathrm{O}_{3}$ & $\mathrm{~N}$ & $300-800$ & $\mathrm{CO}$ & $\mathrm{RT}$ & $47 \mathrm{ppm}$ & {$[93]$} \\
$\mathrm{WO}_{3}$ & $\mathrm{~N}$ & $\sim 100$ & $\mathrm{CO}$ & 300 & $\sim 1 \mathrm{ppm}$ & {$[88]$} \\
$\mathrm{WO}_{3}$ & $\mathrm{~N}$ & $20-140$ & $\mathrm{NH}$ & 350 & $50 \mathrm{ppm}$ & {$[95]$} \\
$\mathrm{V}_{2} \mathrm{O}_{5}$ & $\mathrm{~N}$ & $32-82$ & $\mathrm{NO}$ & 300 & $30 \mathrm{ppb}$ & {$[100]$} \\
$\mathrm{SrTi}_{0.8} \mathrm{Fe}_{0.2} \mathrm{O}_{3-\delta}$ & $\mathrm{N}$ & $\sim 10$ & $\mathrm{NH}$ & $\mathrm{RT}$ & $30 \mathrm{ppb}$ & {$[86]$} \\
\hline \hline
\end{tabular}

$\mathrm{N}$, Nonwoven; $\mathrm{S}$, single

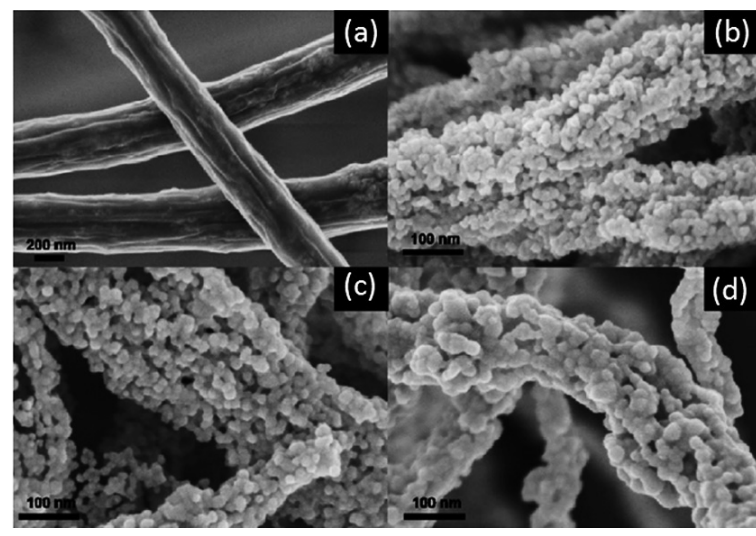

Fig. 9. SEM images of (a) as prepared PVA/indium acetate composite nanofibers, (b) after annealing at $T_{\text {an }}=400{ }^{\circ} \mathrm{C}$, (c) $T_{\text {an }}=500{ }^{\circ} \mathrm{C}$, and (d) $T_{\text {an }}=600{ }^{\circ} \mathrm{C}$. (Reprinted with permission from Ref. [88]. Copyright 2010 Elsevier.)

It is necessary to note that metal oxide nanofibers can be fabricated using various methods [83-87]. Electrospinning also can be used for metal oxide nanofibers fabrication [88, 89]. For example, there are reports related to nanofibers of $\mathrm{TiO}_{2}$ [90-92], $\mathrm{SnO}_{2}[91,93,94], \mathrm{WO}_{3}$ [95], $\mathrm{TiO}_{2}: \mathrm{LiCl}$ [96], $\mathrm{ZnO}$ [97], $\mathrm{SrTi}_{0.8} \mathrm{Fe}_{0.2} \mathrm{O}_{3-\delta}$ [98], etc. Usually for preparing metal oxide nanofibers a hybrid solution, which is a mixture of the metal oxide sol precursor, polymer, and solvent is used. In order to make the inorganic nanoparticles effectively disperse in polymer, sometimes a surfactant is needed. At that it is necessary to take into account that for preparing metal oxides fibers the sintering at elevated temperatures usually is required. This thermal treatment is necessary for both the transformation of hydroxides in oxides and decomposition and removing polymeric components used for electrospinning. Fig. 9 shows SEM images of $\operatorname{In}_{2} \mathrm{O}_{3}$-based nanofibers deposited using PVA/indium acetate composite with following annealing in oxygen containing atmosphere. As it is seen, metal oxides in nanofibers are polycrystalline.

Research, however, has shown that feature of nanofiber configuration and dimensional factor play positive role during design of conductometric gas sensors. Extremely high porosity is the main advantage of these sensors, which show very good operating characteristics (great and fast response) in comparison with sensors based on conventional materials. Parameters of several gas sensors designed on the base of metal oxide nanofibers are listed in Table 6.

\section{OUTLOOKS}

Our discussion has shown that there is no universal material suitable for application in all types of conductometric gas sensors. For example, even mostly used metal oxides such as tin dioxide and indium oxides have both advantages and disadvantages for application in different gas sensors. Therefore, the choice of one or other material would be determined by exploitation conditions, and the requirements to sensors. Moreover, during the choice of either methods and technological parameters of metal oxide synthesis, deposition and modification, which should guarantee the achievement of necessary electrophysical and structural properties, we have to take into account a great number of requirements presented to 
sensor designed. We have to take into account the device destination, the nature of detected gas, required sensitivity, exploitation conditions, required rate of sensor response and so on. The configuration of designed sensors is also important factor influencing our choice. For example, oneelectrode and two-electrode gas sensors have different requirements to material resistance for their optimal functioning. At that we need to recognize that there is no universal decision for simultaneous optimization of all sensor parameters. As a rule, an improvement of one parameter is accompanied by worsening of another one. Therefore, on all stages of gas sensor design and fabrication one should seek a compromise between different parameters of designed gas sensors: between sensitivity and stability; between selectivity and sensitivity; between stability, sensitivity and sensor cost; and so on (see Fig. 10).

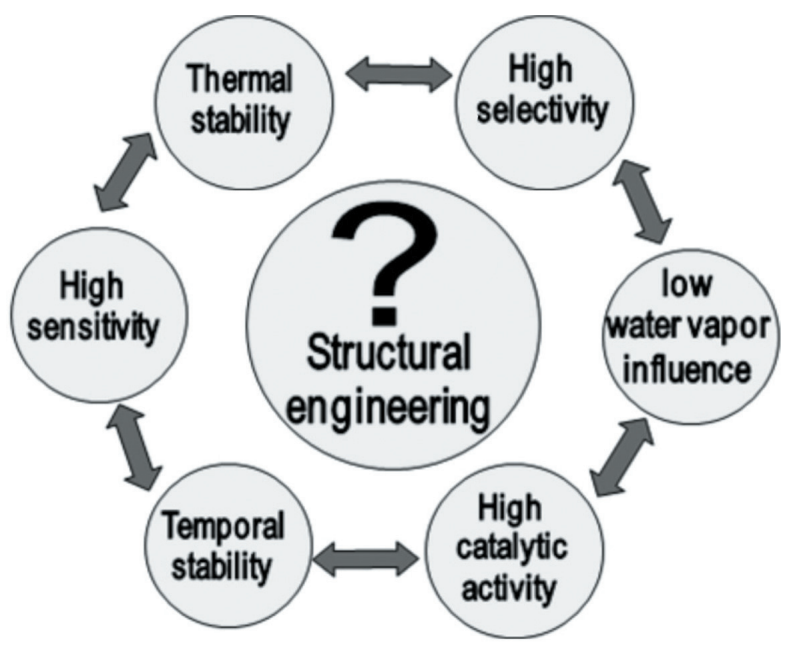

Fig. 10. Parameters of sensing materials depending on the methods of structural engineering.

Good technological effectiveness and processibility (see Fig. 11), i.e., the ability to produce, under control and with reproducibility, powders, films, and ceramics with the required structural and morphological properties, is also an important criterion in selecting a material for a gas sensor. Both complicated techniques and the absence of a technological base for mass production can also considerably limit the application of a particular sensing material. This confirms again that, for practical use, considerations of stability, reliability, and technological effectiveness are determinative.

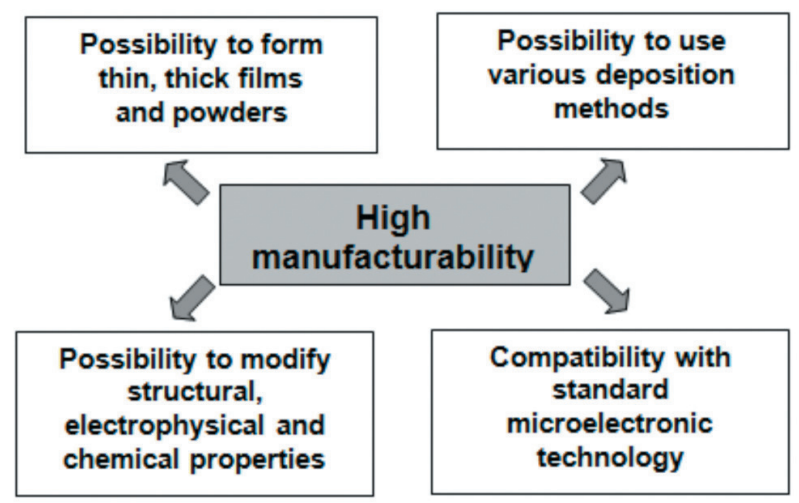

Fig. 11. Factors sustaining the high manufacturability of sensing material.

\section{ACKNOWLEDGMENT}

This work was supported by the Ministry of Education, Science and Technology of Korea (2011-0028736), by the Korean Science and Engineering Foundation (KOSEF) NCRC grant (No. R15-2008-006-01002-0) funded by the Korean government (MEST), and by Basic Science Research Program through the National Research Foundation of Korea (NRF) funded by the Ministry of Education, Science and Technology (2012R1A1A2041564).

\section{REFERENCES}

[1] G. Korotcenkov and V. Sysoev, "Conductometric metal oxide gas sensors”, In: G. Korotcenkov (ed). Chemical Sensors, Vol. 4: Solid State Devices. Momentum Press, New York, pp. 39-186, 2011.

[2] D. Kohl, "Surface processes in the detection of reducing gases with $\mathrm{SnO}_{2}$-based devices", Sens. Actuators, Vol. 18, pp. 71-113, 1989.

[3] N. Barsan, M. Schweizer-Berberich, and W. Gopel, "Fundamental and practical aspects in the design of nanoscaled $\mathrm{SnO}_{2}$ gas sensors. A status report", Fresen. J. Anal. Chem., Vol. 365, pp. 287-304, 1999.

[4] A. Gurlo, "Interplay between $\mathrm{O}_{2}$ and $\mathrm{SnO}_{2}$ : Oxygen ionosorption and spectroscopic evidence for adsorbed oxygen”, ChemPhysChem., Vol. 7, pp. 2041-2052, 2006.

[5] M. Batzill, "Surface science studies of gas sensing materials: $\mathrm{SnO}_{2}$ ", Sensors, Vol. 6, pp. 1345-1366, 2006.

[6] N. Barsan and U. Weimar, "Conduction model of 
metal oxide gas sensors", J. Electroceram., Vol. 7, No. 3, pp. 143-167, 2001.

[7] V. Brynzari, G. Korotchenkov, and S. Dmitriev, "Theoretical study of semiconductor thin film gas sensitivity: Attempt to consistent approach", $J$. Electron. Technol., Vol. 33, pp. 225-235, 2000.

[8] D.E. Williams, "Semiconducting oxides as gassensitive resistors", Sens. Actuators B, Vol. 57, pp. 116, 1999.

[9] G. Korotcenkov, "Metal oxides for solid state gas sensors: What determines our choice?", Mater. Sci. Eng. B, Vol. 139, pp. 1-23, 2007.

[10] G. Korotcenkov (ed). Chemical Sensors, Vol. 1-3: Fundamentals of Sensing Materials. Momentum Press, New York, 2010-2011.

[11] G. Korotcenkov, "Practical aspects in design of oneelectrode semiconductor gas sensors: status report", Sens. Actuators B, Vol. 121, pp. 664-678, 2007.

[12] G. Korotcenkov and B.K. Cho, "Ozone measuring: What can limit the application of $\mathrm{SnO}_{2}$-based gas sensors?", Sens. Actuators B, Vol. 161, pp. 28-44, 2012.

[13] J. L. Solis, S. Saukko, L. Kish, C.G. Granqvist, and V. Lantto, "Semiconductor gas sensors based on nanostructured tungsten oxide", Thin Solid Films, Vol. 391, pp. 255-260, 2001.

[14] U. Hoefer U., J. Frank J., and M. Fleischer, "High temperature $\mathrm{Ga}_{2} \mathrm{O}_{3}$ gas sensors and $\mathrm{SnO}_{2}$ gas sensors: A comparison", Sens. Actuators B, Vol. 78, pp. 6-11, 2001.

[15] G. K. Mor, M. A. Carvalho, O. K. Varghese, M. V. Pishko, and C. A. Grimes, “A room-temperature $\mathrm{TiO}_{2}$-nanotube hydrogen sensor able to self-clean photoactively from environmental contamination", J. Mater. Res., Vol. 19, pp. 628-634, 2004.

[16] A. B. Gadkari, T. J. Shinde, and P. N. Vasambekar, "Ferrite gas sensors", IEEE Sensor J., Vol. 11, No. 4, pp. 849-861, 2011.

[17] H. Meixner, U. Lampe, "Metal oxide sensors", Sens. Actuators B, Vol. 33, pp. 198-202, 1999.

[18] J. Tamaki, K. Shimanoe, Y. Yamada, Y. Yamamoto, N. Miura, and N. Yamazoe, "Dilute hydrogen sulfide sensing properties of $\mathrm{CuO}-\mathrm{SnO}_{2}$ thin film prepared by low-pressure evaporation method", Sens. Actuators B, Vol. 49, pp. 121-125, 1998.

[19] G. Korotcenkov and B. K. Cho, "Instability of metal oxide-based conductometric gas sensors and approaches to stability improvement", Sens. Actuators B, Vol. 156, pp. 527-538, 2011.

[20] G. Korotcenkov, A. Cornet, E. Rossinyol, J. Arbiol, V. Brinzari, and Y. Blinov, "Faceting characterization of $\mathrm{SnO}_{2}$ nanocrystals deposited by spray pyrolysis from $\mathrm{SnCl}_{4}-5 \mathrm{H}_{2} \mathrm{O}$ water solution", Thin Solid Films, Vol. 471, pp. 310-319, 2005.

[21] G. Korotcenkov, V. Brinzari, J. R. Stetter, I. Blinov, and V. Blaja, "The nature of processes controlling the kinetics of indium oxide-based thin film gas sensor response", Sens. Actuators B, Vol. 128, pp. 51-63, 2007.

[22] G. Korotcenkov and B. K. Cho, "Thin film $\mathrm{SnO}_{2}$ based gas sensors: Film thickness influence", Sens. Actuators B, Vol. 142, pp. 321-330, 2009.

[23] G. Korotcenkov, "Gas response control through structural and chemical modification of metal oxides: State of the art and approaches", Sens. Actuators B, Vol. 107, pp. 209-232, 2005.

[24] G. Korotcenkov, "The role of morphology and crystallographic structure of metal oxides in response of conductometric-type gas sensors", Mater. Sci. Eng. R., Vol. 61, pp. 1-39, 2008.

[25] V. Brinzari, G. Korotcenkov, and V. Golovanov, "Factors influencing the gas sensing characteristics of tin dioxide films deposited by spray pyrolysis: understanding and possibilities for control", Thin Solid Films, Vol. 391/392, pp. 167-175, 2001.

[26] G. Korotcenkov, V. Golovanov, A. Cornet, V. Brinzari, J. Morante, and M. Ivanov, "Distinguishing feature of metal oxide films' structural engineering for gas sensor application", J. Phys.: Confer. Series, Vol. 15, pp. 256-261, 2005.

[27] N. Yamazoe, Y. Kurokawa, and T. Seiyama, "Effects of additives on semiconductor gas sensors", Sens. Actuators, Vol. 4, pp. 283-289, 1983.

[28] G. Korotcenkov, S. D. Han, B. K. Cho, and V. Brinzari, "Grain size effects in sensor response of nanostruc-tured $\mathrm{SnO}_{2}$ - and $\mathrm{In}_{2} \mathrm{O}_{3}$-based conductometric gas sensor", Crit. Rev. Sol. St. Mater. Sci., Vol. 34, No. 1-2, pp.1-17, 2009.

[29] A. Gurlo, M. Ivanovskaya, N. Barsan, M. Schweizer-Berberich, U. Weimar, W. Gopel, and A. Dieguez, "Grain size control in nanocrystalline $\mathrm{In}_{2} \mathrm{O}_{3}$ semiconductor sensors", Sens. Actuators B, Vol. 44, pp. 327-333, 1997.

[30] G. Korotcenkov, V. Brinzari, A. Cerneavschi, M. 
Ivanov, V. Golovanov, A. Cornet, J. Morante, A. Cabot, and J. Arbiol, "The influence of film structure on $\mathrm{In}_{2} \mathrm{O}_{3}$ gas response", Thin Solid Films, Vol. 460, pp. 308-316, 2004.

[31] G. Korotcenkov and B.K. Cho, "The role of the grain size in thermal stability of nanostructured $\mathrm{SnO}_{2}$ and $\mathrm{In}_{2} \mathrm{O}_{3}$ metal oxides films aimed for gas sensor application", Prog. Crystal. Growth, Vol. 58, pp. 167-208, 2012.

[32] G. Korotcenkov, V. Brinzari, M. Ivanov, A. Cerneavschi, J. Rodriguez, A. Cirera, A. Cornet, and J. Morante, "Structural stability of $\mathrm{In}_{2} \mathrm{O}_{3}$ films deposited by spray pyrolysis during thermal annealing”, Thin Solid Films, Vol. 479, pp. 38-51, 2005.

[33] G. Korotcenkov, V. Brinzari, and I. Boris, “( $\mathrm{Cu}, \mathrm{Fe}$, Co or Ni)-doped $\mathrm{SnO}_{2}$ films deposited by spray pyrolysis: Doping influence on film morphology", J. Mater. Sci., Vol. 43, No. 8, pp. 2761-2770, 2008.

[34] G. Korotcenkov and S. D. Han, "(Cu, Fe, Co and $\mathrm{Ni}$ )-doped $\mathrm{SnO}_{2}$ films deposited by spray pyrolysis: Doping influence on thermal stability of $\mathrm{SnO}_{2}$ film structure", Mater. Chem. Phys., Vol. 113, pp. 756763, 2009.

[35] Z. R. Dai, Z. W. Pan, and Z. L. Wang, "Ultra-long single crystalline nanoribbons of tin oxide", Sol. St. Commun., Vol. 118, pp. 351-354, 2001.

[36] Z. R. Dai, Z. W. Pan, and Z. L. Wang, "Novel nanostructures of functional oxides ssynthesized by thermal evaporation", Adv. Funct. Mater., Vol. 13, No.1, pp. 9-24, 2003.

[37] X. L. Ma, Y. Li, and Y. L. Zhu, "Growth mode of the $\mathrm{SnO}_{2}$ nanobelts synthesized by rapid oxidation", Chem. Phys. Let., Vol. 376, pp. 794-798, 2003.

[38] L. Huang, L. Pu, Y. Shi, R. Zhang, B. Gu, Y. Du, and S. Wright, "Controlled growth of well-faceted zigzag tin oxide mesostructures", Appl. Phys. Let., Vol. 87, p. 163124, 2005.

[39] M. Law, H. Kind, B. Messer, F. Kim, and P.D. Yang, "Photochemical sensing of $\mathrm{NO}_{2}$ with $\mathrm{SnO}_{2}$ nanoribbon nanosensors at room temperature", Angew. Chem. Int. Ed., Vol. 41, pp. 2405-2408, 2002.

[40] J. D. Prades, R. Jimenez-Diaz, F. HernandezRamirez, S. Barth, A. Cirera, A. RomanoRodriguez, S. Mathur, and J. R. Morante, "Equivalence between thermal and room temperature UV light-modulated responses of gas sensors based on individual $\mathrm{SnO}_{2}$ nanowires", Sens. Actuators B, Vol. 140, pp. 337-342, 2009.

[41] C. Li, D. Zhang, X. Liu, S. Han, T. Tang, J. Han, and $\mathrm{C}$. Zhou, " $\mathrm{In}_{2} \mathrm{O}_{3}$ nanowires as chemical sensors", Appl. Phys. Lett., Vol. 82, pp. 1613-1615, 2003.

[42] D. H. Zhang, Z. Q. Liu, C. Li, T. Tang, X.L. Liu, S. Han, B. Lei, and C. W. Zhou, "Detection of $\mathrm{NO}_{2}$ down to ppb levels using individual and multiple $\mathrm{In}_{2} \mathrm{O}_{3}$ nanowire devices", Nano Lett., Vol. 4, pp. 1919-1924, 2004.

[43] M.-W. Ahn, K.-S. Park, J.-H. Heo, J.-G. Park, D.W. Kim, K. J. Choi, J.-H. Lee, and S.-H. Hong, "Gas sensing properties of defect-controlled $\mathrm{ZnO}$ nanowire gas sensor”, Appl. Phys. Lett., Vol. 93, 263103, 2008.

[44] A. Kolmakov, D. O. Klenov, Y. Lilach, S. Stemmer, and M. Moskovits, "Enhanced gas sensing by individual $\mathrm{SnO}_{2}$ nanowires and nanobelts functionalized with Pd catalyst particles", Nano Lett., Vol. 5, pp. 667-673, 2005.

[45] J. M. Baik, M. H. Kim, C. Larson, C. T. Yavuz, G. D. Stucky, A. M. Wodtke, and M. Moskovits, "Pdsensitized single vanadium oxide nanowires: Highly responsive hydrogen sensing based on the metalinsulator transition", Nano Lett., Vol. 9, pp. 39803984, 2009.

[46] C. S. Rout, G. U. Kulkarni, and C. N. R. Rao, "Room temperature hydrogen and hydrocarbon sensors based on single nanowires of metal oxides", J. Phys. D, Vol. 40, pp. 2777-2782, 2007.

[47] L. H. Qian, K. Wang, Y. Li, H. T. Fang, G. H. Lu, and X. L. Ma, "CO sensor based on Au-decorated $\mathrm{SnO}_{2}$ nanobelt", Mater. Chem. Phys., Vol. 10, pp. 82-84, 2006.

[48] Q. Kuang, C. S. Lao, Z. Li, Y. Z. Liu, Z. X. Xie, L. S. Zheng, and Z. L. Wang, "Enhancing the photonand gas-sensing properties of a single $\mathrm{SnO}_{2}$ nanowire based nanodevice by nanoparticle surface functionalization", J. Phys. Chem. C, Vol. 112, pp. 11539-11544, 2008.

[49] T. Y. Wei, P. H. Yeh, S. Y. Lu, and Z. L. Wang, "Gigantic enhancement in sensitivity using Schottky contacted nanowire nanosensor", J. Am. Chem. Soc., Vol. 131, pp. 17690-17695, 2009.

[50] J. S. Tresback and N. P. Padture, "Low-temperature gas sensing in individual metal-oxide-metal heterojunction nanowires", J. Mater. Res., Vol. 23, 
pp. 2047-2052, 2008.

[51] L. Liao, H. X. Mai, Q. Yuan, H. B. Lu, J. C. Li, C. Liu, C. H. Yan, Z. X. Shen, and T. Yu, "Single $\mathrm{CeO}_{2}$ nanowire gas sensor supported with $\mathrm{Pt}$ nanocrystals: Gas sensitivity, surface bond states, and chemical mechanism", J. Phys. Chem. C, Vol. 112, pp. 9061-9065, 2008.

[52] V. Kumar S. Sen, K. P. Muthe, N. K. Gaur, S. K. Gupta, and J. V. Yakhmi, "Copper doped $\mathrm{SnO}_{2}$ nanowires as highly sensitive $\mathrm{H}_{2} \mathrm{~S}$ gas sensor", Sens. Actuators B, Vol. 138, pp. 587-590, 2009.

[53] L. Liao, H. B. Lu, J. C. Li, C. Liu, D. J. Fu, and Y. L. Liu, "The sensitivity of gas sensor based on single $\mathrm{ZnO}$ nanowire modulated by helium ion radiation", Appl. Phys. Lett., Vol. 91, p. 173110, 2007.

[54] Z. M. Zeng, K. Wang, Z. X. Zhang, J. J. Chen, and W. L. Zhou, "The detection of $\mathrm{H}_{2} \mathrm{~S}$ at room by using individual indium oxide nanowire transistors", Nanotechnol., Vol. 20, p. 045503, 2009.

[55] Y. Liu and M. Liu, "Growth of aligned squareshaped $\mathrm{SnO}_{2}$ tube arrays", Adv. Mater., Vol. 15, No. 1, pp. 57-62, 2005.

[56] P. Feng, Y. X. Xue, Y. G. Liu, Q. Wan, and T. H. Wang, "Achieving fast oxygen response in individual $\beta-\mathrm{Ga}_{2} \mathrm{O}_{3}$ nanowires by ultraviolet illumination", Appl. Phys. Lett., Vol. 89, p. 112114, 2006.

[57] Z. Lin, W. Song, and H. Yang, "Highly sensitive gas sensor based on coral-like $\mathrm{SnO}_{2}$ prepared with hydrothermal treatment", Sens. Actuators B, Vol. 173, pp. 22-27, 2012.

[58] J.-H. Lee, "Gas sensors using hierarchical and hollow oxide nanostructures: Overview", Sens. Actuators B, Vol. 140, pp. 319-336, 2009.

[59] K. Okuyama, M. Abdullan, I. W. Llenggoro, and F. Iskandar, "Preparation of functional nanostructured particles by spray drying”, Adv. Powder Technol., Vol. 17, pp. 587-611, 2006.

[60] P. Colombo, C. Vakifahmetoglu, and S. Costacurta, "Fabrication of ceramic components with hierarchical porosity", J. Mater. Sci., Vol. 45, pp. 5425-5455, 2010.

[61] M. Hayashi, T. Hyodo, Y. Shimizu, and M. Egashira, "Effects of microstructure of mesoporous $\mathrm{SnO}_{2}$ powders on their $\mathrm{H}_{2}$ sensing properties", Sens. Actuators B, Vol. 141, pp. 465-470, 2009.

[62] A. Rothschild and H. L. Tuller, "Gas sensors: New materials and processing approaches", $J$ Electroceram., Vol. 17, pp. 1005-1012, 2006.

[63] Y. Wang, A. S. Angelatos, and F. Caruso, "Template synthesis of nanostructured materials via layer-by-layer assembly", Chem. Mater., Vol. 20, pp. 848-858, 2008.

[64] T. L. Wadea and J.-E. Wegrowe, "Template synthesis of nanomaterials", Eur. Phys. J., Appl. Phys., Vol. 29, pp. 3-22, 2005.

[65] W. Yue and W. Zhou, "Crystalline mesoporous metal oxide", Prog. Nat. Sci., Vol. 18, pp. 13291338, 2008.

[66] C. Sanchez, C. Boissière, D. Grosso, C. Laberty, and L. Nicole, "Design, synthesis, and properties of inorganic and hybrid thin films having periodically organized nanoporosity", Chem. Mater., Vol. 20, pp. 682-737, 2008.

[67] O. K. Varghese, D. Gong, M. Paulose, K. G. Ong, and C.A. Grimes, "Hydrogen sensing using titania nanotubes", Sens. Actuators B, Vol. 93, pp. 338344, 2003.

[68] Y. Li, X. Yu, and Q. Yang, "Fabrication of $\mathrm{TiO}_{2}$ nanotube thin films and their gas sensing properties”, J. Sensors, Vol. 2009, 402174, 2009.

[69] S. Rani, S. C. Roy, M. Paulose, O. K. Varghese, G. K. Mor, S. Kim, S. Yoriya, T. J. LaTempa, and C. A. Grimes, "Synthesis and applications of electrochemically self-assembled titania nanotube arrays", Phys. Chem. Chem. Phys., Vol. 12, pp. 2780-2800, 2010.

[70] J.-H. Jeun and S.-H. Hong, "CuO-loaded nanoporous $\mathrm{SnO}_{2}$ films fabricated by anodic oxidation and RIE process and their gas sensing properties", Sens. Actuators B, Vol. 151, pp. 1-7, 2010.

[71] M. Tiemann, "Porous metal oxides as gas sensors", Chem. Eur. J., Vol. 13, pp. 8376-8388, 2007.

[72] Y. Shimizu, Y. Hyodo, and M. Egashira, "Mesoporous semiconducting oxides for gas sensor application”, J. Eur. Ceram. Soc., Vol. 24, pp. 13891398, 2004.

[73] Y. Shimizu, A. Jono, T. Hyodo, and M. Egashira, "Preparation of large mesoporous $\mathrm{SnO}_{2}$ powders for gas sensor application", Sens. Actuators B, Vol. 108, pp. 56-61, 2005.

[74] G. S. Devi, T. Hyodo, Y. Shimizu, and M. Egashira, "Synthesis of mesoporous $\mathrm{TiO}_{2}$-based powders and their gas-sensing properties", Sens. Actuators B, Vol. 87, pp. 122-129, 2002. 
[75] T. Hyodo, Y. Shimizu, and M. Egashira, "Gassensing properties of ordered mesoporous $\mathrm{SnO}_{2}$ and effects of coating thereof', Sens. Actuators B, Vol. 93, pp. 590-600, 2003.

[76] T. Wagner, T. Waitz, J. Roggenbuck, M. Froeba, C.-D. Kohl, and M. Tiemann, "Ordered mesoporous $\mathrm{ZnO}$ for gas sensing", Thin Solid Films, Vol. 515, pp. 8360-8363, 2007.

[77] Q. Liu, W.-M. Zhang, Z.-M. Cui, B. Zhang, L.-J. Wan, and W.-G. Song, "Aqueous route for mesoporous metal oxides using inorganic metal source and their applications", Micropor. Mesopor. Mater., Vol. 100, pp. 233-240, 2007.

[78] K. Choi, H. R. Kim, and J. H. Lee, "Enhanced CO sensing characteristics of hierarchical and hollow $\mathrm{In}_{2} \mathrm{O}_{3}$ microspheres", Sens. Actuators B, Vol. 138, 4 pp. 97-503, 2009.

[79] E. Rossinyol, A. Prim, E. Pellicer, J. Rodriguez, F. Peiry, A. Cornet, J. R. Morante, B. Tian, T. Bo, and D. Zhao, "Mesostructured pure and coppercatalyzed tungsten oxide for $\mathrm{NO}_{2}$ detection", Sens. Actuators B, Vol. 126, pp. 18-23, 2007.

[80] E. Rossinyol, A. Prim, E. Pellicer, J. Arbiol, F. Hernandez-Ramirez, F. Peiry, A. Cornet, J.R. Morante, L.A. Solovyov, B. Tian., T. Bo, and D. Zhao, "Synthesis and characterization of chromiumdoped mesoporous tungsten oxide for gas sensing applications", Adv. Funct. Mater., Vol. 17, pp. 1801-1806, 2007.

[81] L. He, Y. Jia, F. Meng, M. Li, and J. Liu, "Development of sensors based on CuO-doped $\mathrm{SnO}_{2}$ hollow spheres for ppb level $\mathrm{H}_{2} \mathrm{~S}$ gas sensing", J. Mater. Sci., Vol. 44, pp. 4326-4333, 2009.

[82] T. Hyodo, N. Nishida, Y. Shimizu, and M. Egashira, "Preparation and gas-sensing properties of thermally stable mesoporous $\mathrm{SnO}_{2}$ ", Sens. Actuators B, Vol. 83, pp. 209-215, 2002.

[83] C. Shao, H. Kim, J. Gong, and D. Lee, "A novel method for making silica nanofibers by using electrospun fibers of polyvinyl alcohol/silica composite as precursor", Nanotechnology, Vol. 13, 635-637, 2002.

[84] Z. Miao, D. Xu, J. Ouyang, G. Guo, X. Zhao, and $\mathrm{Y}$. Tang, "Electrochemically induced sol-gel sreparation of single-crystalline $\mathrm{TiO}_{2}$ nanowires", Nano Lett., Vol. 2, pp. 717-720, 2002.

[85] B. Ding, C. Kim, H. Kim, M. Seo, and S. Park, "Titanium dioxide nanofibers prepared by using electrospinning method", Fiber. Polym., Vol. 5, pp. 105-109, 2004.

[86] I. Raible, M. Burghard, U. Schlecht, A. Yasuda, and T. Vossever, " $\mathrm{V}_{2} \mathrm{O}_{5}$ nanofibers: Novel gas sensors with extremely high sensitivity and selectivity to amines", Sens. Actuators B, Vol. 106, pp. 730-735, 2005.

[87] R. Luoh and H.T. Hahn, "Electrospun nanocomposite fiber mats as gas sensors", Composites. Sci. Technol., Vol. 66, pp. 2436-2441, 2006.

[88] S. K. Lim, S. H. Hwang, D. Chang, and S. Kim, "Preparation of mesoporous $\operatorname{In}_{2} \mathrm{O}_{3}$ nanofibers by electrospinning and their application as a $\mathrm{CO}$ gas sensor", Sens. Actuators B, Vol. 149, pp. 28-33, 2010.

[89] J.-A. Park, J. Moon, S.-J. Lee, S. H. Kim, T. Zyung, and H.Y. Chu, "Structure and $\mathrm{CO}$ gas sensing properties of electrospun $\mathrm{TiO}_{2}$ nanofibers", Mater. Lett., Vol. 64, pp. 255-257, 2010.

[90] I. Kim, A. Rothschild, B. Lee, D. Kim, S. Jo, and H. Tuller, "Ultrasensitive chemiresistors based on electrospun $\mathrm{TiO}_{2}$ nanofibers", Nano Lett., Vol. 6, pp. 2009-2013, 2006.

[91] Y. Zhang, X. He, J. Li, Z. Miao, and F. Huang, "Fabrication and ethanol-sensing properties of micro gas sensor based on electrospun $\mathrm{SnO}_{2}$ nanofibers", Sens. Actuators B, Vol. 132, pp. 67-73, 2008.

[92] O. Landau, A. Rothschild, and E. Zussman, "Processing-microstructure-properties correlation of ultrasensitive gas sensors produced by electrospinning", Chem. Mater., Vol. 21, pp. 9-11, 2009.

[93] A. Yang, X. Tao, and R. Wang, "Room temperature gas sensing properties of $\mathrm{SnO}_{2} /$ multiwallcarbonnanotube composite nanofibers", Appl. Phys. Lett., Vol. 91, p. 133110, 2007.

[94] Y. Wang, I. Ramos, and J. Santiago-Aviles, "Detection of moisture and methanol gas using a single electrospun tin oxide nanofiber", IEEE Sensors J., Vol. 7, pp. 1347-1348, 2007.

[95] G. Wang, Y. Ji, X. Huang, X. Yang, P. Gouma, and M. Dudley, "Fabrication and characterization of polycrystalline $\mathrm{WO}_{3}$ nanofibers and their application for ammonia sensing". J. Phys. Chem. $B$, Vol. 110, pp. 23777-23782, 2006.

[96] Z. Li, H. Zhang, W. Zheng, W. Wang, H. Huang, C. 
Wang, A. MacDiarmid, and Y. Wei, "Highly sensitive and stable humidity nanosensors based on $\mathrm{LiCl}$ doped $\mathrm{TiO}_{2}$ electrospun nanofibers", J. Am. Chem. Soc., Vol. 130, pp. 5036-5037, 2008.

[97] M. Yang, T. Xie, L. Peng, Y. Zhao, and D. Wang, "Fabrication and photoelectric oxygen sensing characteristics of electrospun Co doped $\mathrm{ZnO}$ nanofibers", Appl. Phys. A-Mat. Sci. Process., Vol. 89, pp. 427-430, 2007.

[98] K. Sahner, P. Gouma, and R. Moos, "Electrodeposited and sol-gel precipitated p-type $\mathrm{SrTi}_{1-\mathrm{x}}$ $\mathrm{Fe}_{\mathrm{x}} \mathrm{O}_{3-\delta}$ semiconductors for gas sensing", Sensors,
Vol. 7, pp. 1871-1886, 2007.

[99] G. Wang, Y. Ji, X. Huang, X. Yang, P. Gouma, and M. Dudley, "Fabrication and characterization of polycrystalline $\mathrm{WO}_{3}$ nanofibers and their application for ammonia sensing", J. Phys. Chem. $B$, Vol. 110, pp. 23777-23782, 2006.

[100] N. M. Vuong, H. Jung, D. Kim, H. Kim, and S.-K. Hong, "Realization of an open space ensemble for nanowires: a strategy for the maximum response in resistive sensors", J. Mater. Chem., Vol. 22, pp. 6716-6725, 2012. 